\title{
Holistic approach based assessment of social efficiency of research conducted by higher educational establishments
}

\author{
Iryna Perevozova ${ }^{1}$, Vitalina Babenko $^{2}$, Zoriana Krykhovetska ${ }^{3, *}$, and Iryna Popadynets ${ }^{4}$ \\ ${ }^{1}$ Ivano-Frankivsk National Technical University of Oil and Gas, Entrepreneurship and Marketing Department, 1 Chopin Str., Ivano- \\ Frankivsk, 76000, Ukraine \\ ${ }^{2}$ V. N. Karazin Kharkiv National University, International Business and Economic Theory Department, 4 Svobody Sq., Kharkiv, \\ 61022, Ukraine \\ ${ }^{3}$ Vasyl Stefanyk Precarpathian National University, Department of Finance, 57 Shevchenko Str., Ivano-Frankivsk, 76000, Ukraine \\ ${ }^{4}$ Vasyl Stefanyk Precarpathian National University, Department of Management and Business Administration, 57 Shevchenko Str., \\ Ivano-Frankivsk, 76000, Ukraine
}

\begin{abstract}
Social efficiency of research conducted by higher educational establishments contributes a lot to improving the educational process, the quality of training of specialists, and the teaching skills of scientific and pedagogical staff. A holistic approach in the system of assessment of the social efficiency of higher educational establishments' research, which is interpreted by the authors of the article, makes it possible for higher educational establishments to completely adapt to market requirements, to make adequate managerial decisions and obtain relevant results. The system and structural approach was used in the study, which led to functional and effective application of theoretical provisions, scientific principles and conceptual positions for developing the author's version of forming higher educational establishments' holistic approach based model of social efficiency of research. For the assessment of social efficiency of research, a holistic approach based theoretical and analytical model has been suggested, which integrates 4 subsystems: target, provision, regulatory, management subsystem, which can be assessed by parameters, indicators and criteria of social efficiency of research results. The authors have suggested a system of criteria of social efficiency of research results. On the basis of the elaborated system of criteria assessment of social efficiency of research results of higher educational establishments, the authors have constructed a structural and logical scheme of social efficiency of research results assessment, which shows that on each stage of social efficiency of research results development by means of comparison of the market needs and opportunities of higher educational establishments and rational distribution of endowment funds it is possible to achieve maximization of the social efficiency of research results generalized criterion value. A formal description of the main components of the constructed theoretical-analytical model of the social efficiency of research has been made by means of using the economic and mathematical model and the dependence of its components has been analyzed.
\end{abstract}

\section{Introduction}

The specific nature of higher education, the versatility and multidimensionality of forms of work place particular demands on the assessment of the efficiency of both its activities as a whole and of academic research work (ARW). The issue is complicated by the need to determine not only the economic efficiency of the ARW conducted by higher educational establishment (HEE), but also social efficiency, that is, its impact on the educational process, improving the quality of training specialists, increasing the teaching skills of academic staff, etc.

Social efficiency of ARW in higher education emerges in:

- the development of the potential of higher education by means of the implementation of innovative technologies in the process of training professionals;

- the preservation and production of scientific potential of the higher educational establishment;

- the creation of new curricula, training courses which are relevant to the public needs and introduction of new forms of learning based on the results of ARW;

- dissemination of results of ARW in other higher educational establishments in Ukraine and abroad;

- participation in scientific projects, grant programs, including international ones, etc.

HEEs and scientific research are an integral part of a single whole, provided that this educational establishment strives to make progress and stand out from others by its innovational activity, desire to improve, promote, simplify and enhance any processes in science, economy, production in other spheres of

\footnotetext{
* Corresponding author: krizor1@,rambler.ru
} 
human life [1].

The HEEs of the 21st century increasingly recognize the need for a comprehensive approach that goes beyond traditional management principles. The new approach, which allows to most completely adapt HEEs to today's market requirements, is a holistic one, which is to provide a comprehensive approach in the system of assessment of the ARW efficiency in order to make adequate management decisions and obtain appropriate results.

Holism (from Greek "holos" - all, whole, entire) is a methodological principle and a worldview concept that affirms the integrity and indivisibility of the material and spiritual world [2].

In a broad sense it is a principle of philosophy and science, which consists in admitting qualitative originality and priority of the whole in relation to its parts; in a narrow sense holism implies "philosophy of integrity" developed by the South African philosopher Jan Smuts, who introduced the term "holism" in 1926, based on Aristotle's claim that "the whole is greater than a sum of its parts" [3]. Smuts regards integrity as the highest philosophical category that synthesizes the subjective and objective and is the final reality of existence. Holism is the process of evolution that gives rise to new objects as integral [2]. In gnoseology, holism is based on the following principle: the knowledge of the whole must precede the knowledge of its parts. Many philosophers adhered to this principle. So, Hegel wrote, "... only the whole makes sense". In the $17^{\text {th }}-19^{\text {th }}$ centuries, in the course of scientific advancement, scientists began to consider any system as derived from parts, and believed that the properties of any object can be deduced from the analysis of its elements" [3].

It should be pointed out that holistic ideas have been long known in the West. J. W. Goethe is considered to be the first Western preacher of holistic thinking. He developed his own scientific method Anschauung ("Sense perception"). Another milestone in the history of the holistic paradigm is represented by the works of the German psychologist Max Wertheimer. In early 20th century, he conducted experiments proving that human perception of the environment is holistic, unified and it is supported by logics only after the specification of each individual part of the whole.

Such sciences as cybernetics, catastrophe theory, and complexity science have emerged on the basis of the above-mentioned theories and continue their development. So, complexity science is the source of many new applied fields, including social science [4].

The vitality of the research in this area is based on the fact that in domestic and foreign literature theoretical and methodological basis of the use of the holistic approach for assessing social efficiency of HEEs' scientific research is absent in fact, which does not allow to use its potential to the full.

\section{Research problem and questions}

The problem of the assessment of efficiency of scientific activity of HEEs has been in the focus of attention of such domestic and foreign scientists as A. M. Bondar [5], Yu. G. Bondarenko, S. M. Vyshniovska [1], A. A. Borisov [6], S. Gralka, K. Wohlrabe, L. Bornmann [7], V. A. Karpov, T. S. Koroliova, A. Z. Pidgornyi [8], V. M. Sinchenko [9], Ch. Tse Kuah, K. Yew Wong [10], T. G. Valderrama, T. L. C. M. Groot [11], D. VisbalCadavid, M. Martínez-Gómez, F. Guijarro [12], I. Ye. Zhurba [13], R.-L. Shi, N. He, Y. Liu [14], A. Jain, R. Sharma, P. V. Ilavarasan [15], G. Lebedev, O. Krylov, A. Lelyakov, Y. Mironov, V. Tkachenko, S. Zykov [16], X. Xiong, G.-L. Yang, Zh.-Ch. Guan [17], E. V. Romanov [18]. They defined the criteria and methodology of assessment of the efficiency of HEEs' research and paid great attention to studying their economic efficiency, however, they did not study their social efficiency sufficiently enough. Apart from that, the holistic approach, its theoretical understanding as the most progressive approach to the assessment of social efficiency of research (SER) in the process of forming the market of social orientation, in which the domestic HEEs function, are hardly presented in the scientific works of Ukrainian and foreign scientists and practitioners.

The purpose of this study is to solve the scientific problem of forming methodology of the assessment of SER based on the use of the potential of a holistic approach in the system of HEEs management in market conditions.

The research is based on a systemic-structural approach, which allows using theoretical provisions, scientific principles and conceptual positions functionally and effectively for developing the author's version of the formation of the model of SER of HEEs based on a holistic approach.

\section{Findings of the research}

The problem of determining socio-economic efficiency of scientific and technological research is developed as a problem of making difficult socio-economic decisions. The social results of the implementation of ARW that were conducted in HEEs are considered as additional indicators of their significance and were taken into consideration in approving the decision on the implementation of this scientific direction and on condition of the state support, can be used as information for the HEEs' accreditation. The social effect in the field of higher education appears primarily in the process of transferring new scientific knowledge and new technologies to HEE students. The social efficiency of ARW is assessed in the following areas: participation in the development of new technologies in educational sphere; participation in educational and teaching processes; conservation and development of scientific potential. The immediate component of the level of social effect is the development of new technologies in education. The objective indicators of this direction of ARW social efficiency are as follows: the number of training courses, which are based on the ideas of development; the availability of new forms of learning, as a result of the ARW results' implementation; the 
number of HEEs that use the results of research and development in the educational process. The objective indicators of the impact of the ARW results on the educational and learning process are: the number of lectures and practical classes where the ARW results are used; the amount of published literature on education and methodology, which is based on the results of research and development; the number of students familiarized with the results of research and development (participation in lectures, practical classes, seminars and other forms of study). The objective indicators of the impact of ARW on the preservation and development of scientific potential are: the quota of doctors of sciences and doctoral students participating in ARW in the total number; the quota of candidates of sciences participating in ARW in the total number; the quota of students participating in ARW in the total number; the quota of students participating in ARW in the total number [8].

We consider it necessary to prolong the list of objective indicators of the impact of ARW results on the educational and teaching/learning process with the number of lab classes, trainings, international internships, the number of the carried out projects (including those conducted with the grant support), the number of students participating in international mobility programs. In order to align the scientific titles to the international standards, the Candidate of Economic Sciences is proposed to be replaced by $\mathrm{PhD}$.

For the purpose of unifying, the terms employed in the given article "academic research work", "research and development work", "scientific and technological work" used in national normative documents and scientific works, are suggested to be replaced by "research".

The world practice shows that the idea of a holistic approach extends to management processes, structural actions in an organization, economic efficiency, and corporate identity. Therefore, we suggest using a holistic approach in the assessment of SER, which allows for a coherent approach to the study of this issue. Owing to a holistic approach, integrity is achieved both in theory and in practice. The efficiency of research can be provided only by means of integrated data, bringing them together into a single management system and analyzing them in the course of time in accordance with the set goals and with reference to all the factors of influence. The efficiency of research can be achieved only if it is considered from the point of view of systemic integrity, which involves the integration and analysis of data obtained from different sources.

It is the holistic approach to the assessment of HEEs' SER that makes it possible to fully use the existing types of assessment and to form a development strategy of HEEs' researches in order to improve their social efficiency.

The theoretical and analytical model of SER is constructed on the basis of the holistic approach (XYZmodels), which is described by the following subsystems: "X" - target subsystem, "Y" - subsystem of provision, "XY" - regulatory subsystem, "Z" management subsystem, which can be assessed by the parameters, indicators, criteria of social efficiency of research results (SERR) (Fig. 1) [19].

The target subsystem " $\mathrm{X}$ " (development of social efficiency) demonstrates the management cycle (set of stages, processes, functions that should be performed in order to achieve the goal (obtaining the results) [19]. The set of processes, which need to be implemented for forming of social efficiency, is determined by the factors of reaching goals, which are divided into macro- and micro-levels ("Y" subsystem).

The macro-level factors affecting SERR comprise:

$\mathrm{Y}_{\text {macro1 }}-$ influence on the development of fundamental science, the most important applied research and development;

$\mathrm{Y}_{\text {macro2 }}$ - increase in the efficiency of regulating science and technology development by the state;

$\mathrm{Y}_{\text {macro3 }}$ - influence on improvement of national innovation system;

$\mathrm{Y}_{\text {macro4 }}$ - increase in the efficiency of using the results of scientific and scientific-technological activities;

$\mathrm{Y}_{\text {macro5 }}$ - influence on development of human resources potential of domestic scientific and technological complex;

$Y_{\text {macro6 }}$ - influence on the growth of integration of science and education;

$\mathrm{Y}_{\text {macro7 }}$ - ensuring the development of international scientific and technological cooperation;

$\mathrm{Y}_{\text {macro8 - emergence of additional social services; }}$

$Y_{\text {macro9 - change of consumer price index; }}$

$\mathrm{Y}_{\text {macro10 }}$ - increase in the provision of housing;

$\mathrm{Y}_{\text {macrol1 }}$ - decline in unemployment, increase in birth rate and reduction of death rate;

$\mathrm{Y}_{\text {macro12 }}$ - the impact of innovative activities on the environment (decreasing acoustic noise level, soil and air pollution, mitigation of the electromagnetic field effect, mechanical vibrations, etc.).

The micro- level factors affecting SERR comprise:

$Y_{\text {microl }}$ - the human resources standard and growth;

$\mathrm{Y}_{\text {micro2 }}$ - the number of patents and other copyrights, based on the results of prospecting, research and development work;

$\mathrm{Y}_{\text {micro3 }}$ - the volume and economic efficiency of contracts on selling intellectual property rights (the number of agreements, the speed of diffusion of innovations, etc.);

$\mathrm{Y}_{\text {micro4 }}$ - the volume and economic efficiency of unique equipment usage services;

$\mathrm{Y}_{\text {micro5 }}$ - the efficiency of the transformation of knowledge, skills, ideas and habits acquired in the process of learning;

$\mathrm{Y}_{\text {micro6 }}$ - the efficiency of transformation of scientific knowledge into innovations (products, production technologies, etc.);

$\mathrm{Y}_{\text {micro7 }}$ - the volume and economic efficiency of consulting services;

$\mathrm{Y}_{\text {micro8 - the level of integration of education, science }}$ and production, which reflects the synergistic effect of research;

$\mathrm{Y}_{\text {micro9 }}$ - the efficiency of use of the endowment (level and rate of growth of financial independence, the volume of raised investments, income from the use of the fund). 

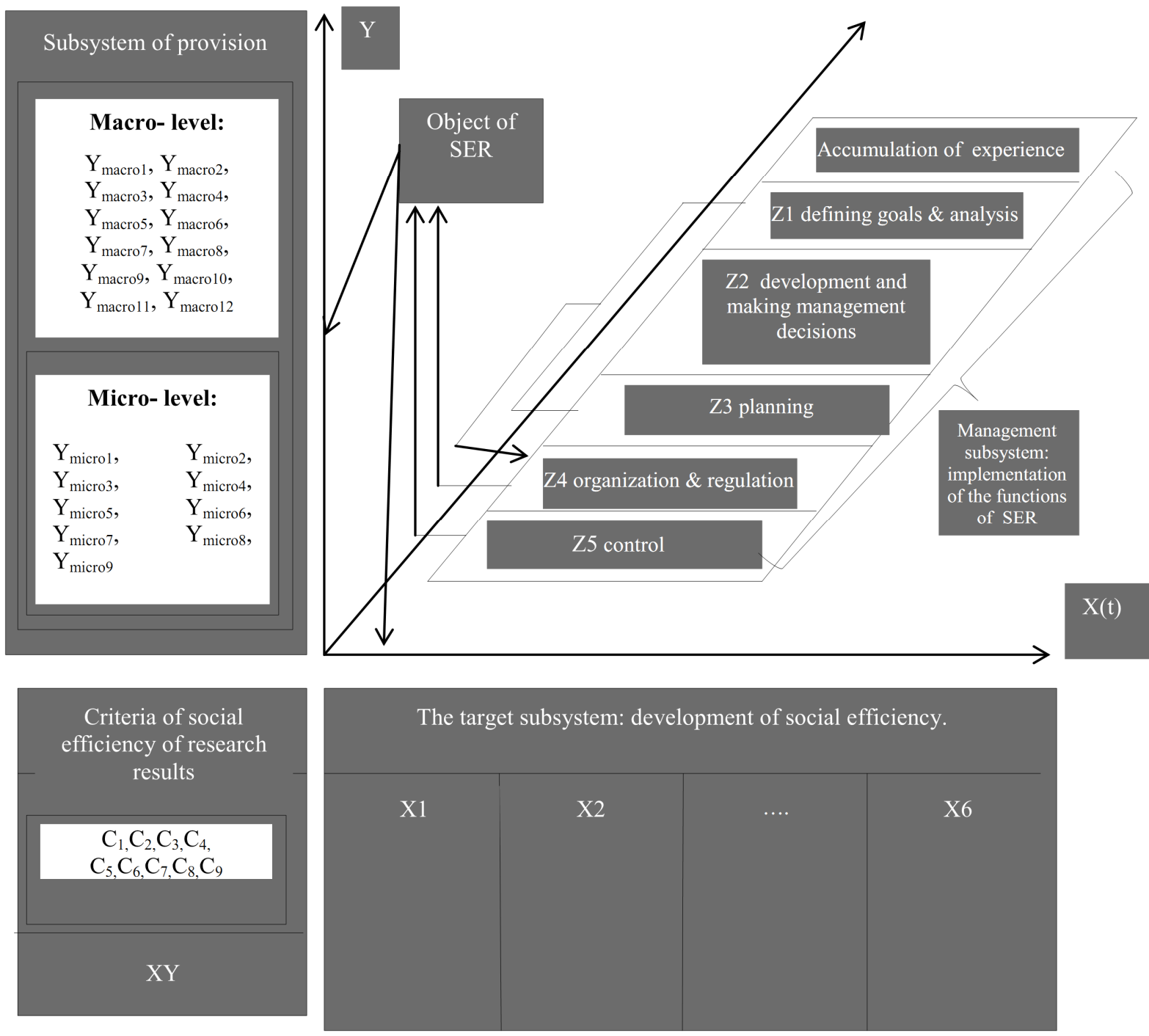

Fig. 1. Theoretical and analytical model of SER.

The management subsystem ("Z") reflects the implementation of the general management functions of the SER on the background of accumulated experience and is aimed at achieving results. Such a system of relations requires the improvement and stabilization of the system of laws, by-laws, instructions, orders, that is, the entire regulatory framework (subsystem "XY").

We suggest the SERR criteria system, which is a combination of static and dynamic microeconomic indicators of the species:

$$
C_{j}=\sqrt[n_{j}]{\prod_{i=1}^{n_{j}} C_{j i}^{W_{j i}}},
$$

where $C_{j}$ is the criterion of social efficiency of the results of the $j$-th direction of scientific research; $C_{j i}$ is the criterion of social efficiency of the results of the $i$-th component of the $j$-th direction of scientific research; $n_{j}$ is the number of evaluated components of social efficiency of the $j$-th direction of scientific research; $w_{i j}$ is the weightage of the $i$-th component of the $j$-th direction of scientific research.

The SERR criteria, which are determined with reference to the data for the reporting period compared to the baseline, are presented below.

The criterion of the assessment of human resources:

$$
C_{1}=\sqrt[2]{\left(\frac{L_{h r}}{L_{h r b}}\right)^{W_{11}}\left(\frac{L_{h r}(r)}{L_{h r b}(b)}\right)^{W_{12}}},
$$

where $L_{h r}$ is the level of human resources of research and development works; $L_{h r b}$ - the level of human resources of the establishment selected as a comparison base; $b, r-$ base and reporting period of assessment; $w_{11}, w_{12}-$ weight coefficients of static and dynamic assessments of human resources $\left(w_{11}+w_{12}\right)=2$.

The criterion of assessment of the social efficiency of creating copyright objects by the results of prospecting, research and development works:

$$
C_{2}=\sqrt[3]{\left(\frac{N_{c o}}{N_{c o b}}\right)^{W_{21}}\left(\frac{M V_{c o}}{C_{c o}}\right)^{W_{22}}\left(\frac{N_{c o}(r)}{N_{c o b}(b)}\right)^{W_{23}}},
$$

where $N_{c o}$ is the number of copyright objects; $N_{c o b}$ is the number of copyright objects created by the establishment selected as a comparison base; $M V_{c o}$ - the market value of copyright objects; $C_{c o}$ - the cost of creating copyright 
objects; $w_{21}, w_{22}, w_{23}$ are the weight coefficients of the relevant criteria of social efficiency of creating copyright objects $\left(w_{11}+w_{12}+w_{23}\right)=3$.

Criteria of the efficiency of contracts on selling intellectual property objects:

$$
C_{3}=\sqrt[4]{\left(\frac{V_{\text {cipo }}}{V_{\text {cipob }}}\right)^{w_{31}}\left(\frac{A V_{\text {ipo }}}{C_{\text {ipo }}}\right)^{W_{32}}\left(\frac{V_{\text {cipo }}(r)}{V_{\text {cipob }}(b)}\right)^{W_{33}}\left(\frac{s_{\text {ipo }}}{s_{\text {ipob }}}\right)^{w_{34}}}
$$

where $V_{\text {cipo }}$ is the volume of contracts on selling intellectual property objects; $V_{\text {cipob }}$ - the volume of contracts on selling intellectual property objects created by the establishment selected as a comparison base; $A V_{i p o}$ - the added value obtained from selling intellectual property objects; $C_{i p o}$ - the cost of creating and promoting intellectual property objects; $S_{i p o}$ - the speed of diffusion of intellectual property objects; $S_{i p o b}-$ the speed of diffusion of intellectual property objects created by the organization selected as a comparison base; $w_{31}$, $w_{32}, w_{33}, w_{34}$ are the weight coefficients of the relevant criteria of the social efficiency of contracts on selling intellectual property rights $\left(w_{31}+w_{32}+w_{33}+w_{34}=4\right)$.

The criterion of the social efficiency of unique equipment usage services provided by HEE:

$$
C_{4}=\sqrt[3]{\left(\frac{V_{\text {ueus }}}{V_{\text {ueusb }}}\right)^{W_{41}}\left(\frac{R_{\text {ueus }}}{C_{\text {ueus }}}\right)^{W_{42}}\left(\frac{V_{\text {ueus }}(r)}{V_{\text {ueus }}(b)}\right)^{W_{43}}},
$$

where $V_{\text {ueus }}$ is the volume of unique equipment usage services provided by HEE; $V_{\text {ueusb }}$ - the volume of unique equipment usage services provided by the establishment selected as a comparison base; $R_{\text {ueus }}$ - revenue from the unique equipment usage services; $C_{\text {ueus }}$ - the cost of unique equipment usage services; $w_{41}, w_{42}, w_{43}$, are the weight coefficients of the relevant criteria of social efficiency of unique equipment usage services $\left(w_{41}+w_{42}+w_{43}=3\right)$.

The criterion of social efficiency of the transformation of knowledge, ideas, skills and abilities acquired in the learning process:

$$
C_{5}=\sqrt[2]{\left(\frac{Q_{s}}{Q_{s b}}\right)^{W_{51}}\left(\frac{Q_{S}(r)}{Q_{s b}(b)}\right)^{W_{52}}},
$$

where $Q_{s}$ is the quota of specialists who have obtained a scientific degree in the total number of the graduate students; $Q_{s b}$ is the quota of specialists who have obtained a scientific degree in the total number of the graduate students in the establishment selected as a comparison base; $w_{51}, w_{52}$ are the weight coefficients of static and dynamic assessments of the quota of specialists who have obtained a scientific degree in the total number of the graduate students $\left(w_{51}+w_{52}=2\right)$.

The criterion of social efficiency of innovating scientific knowledge:

$$
C_{6}=\sqrt[4]{\left(\frac{A V_{i p o}}{M V_{c o}}\right)^{w_{61}}\left(\frac{\left(\frac{A V_{i p o}}{M V_{c o}}\right)(r)}{\left(\frac{A V_{i p o b}}{M V_{c o b}}\right)(b)}\right)^{w_{62}}\left(\frac{A V_{i p o}}{C_{i p o}}\right)^{w_{63}}\left(\frac{P(r)}{P(b)}\right)^{w_{64}}}
$$

where $P$ is the period of innovating scientific knowledge; $A V_{i p o b}$ - added value obtained in the implementation of intellectual property objects in the establishment selected as a comparison base; $M V_{c o b}$ - the market value of copyright objects in the establishment selected as a comparison base; $w_{61}, w_{62}, w_{63}, w_{64}$ are the weight coefficients of the relevant criteria of social efficiency of innovating scientific knowledge $\left(w_{61}+w_{62}+w_{63}+w_{64}=4\right)$.

The criterion of consulting services efficiency:

$$
C_{7}=\sqrt[3]{\left(\frac{V_{c s}}{V_{c s b}}\right)^{W_{71}}\left(\frac{R_{c s}}{c_{c s}}\right)^{W_{72}}\left(\frac{V_{c s}(r)}{V_{c s b}(b)}\right)^{W_{73}}},
$$

where $V_{c s}$ - amount of consulting services; $V_{c s b}$ - amount of consulting services provided by the establishment selected as a comparison base; $R_{c s}$ - revenues from providing consulting services; $C_{c s}-$ cost of consulting services; $w_{71}, w_{72}, w_{73}$ are the weight coefficients of the relevant criteria of consulting services social efficiency $\left(w_{71}+w_{72}+w_{73}=3\right)$.

The criterion of social efficiency of education, science and production integration:

$$
C_{8}=\left[\left(\frac{R_{e s}}{R_{e s b}}\right)^{w_{81}}\left(\frac{V_{o r}}{V_{\text {orb }}}\right)^{w_{82}}\left(\frac{V_{\text {rii }}}{V_{\text {riib }}}\right)^{w_{83}} \times\right.
$$

$\left.\times\left(\frac{R_{e s}(r)}{R_{e s b}(b)}\right)^{w_{84}}\left(\frac{V_{\text {or }}(r)}{V_{\text {orb }}(b)}\right)^{w_{85}}\left(\frac{V_{\text {rii }}(r)}{V_{\text {riib }}(b)}\right)^{w_{86}}\right]^{\frac{1}{6}}$,

where $R_{e s}, R_{e s b}$ is the ratio of educational services provided by the establishment and organization selected as a comparison base, respectively; $V_{o r}, V_{o r b}$ - the volume of orders for researches per specialist received by the establishment and organization selected as a comparison base, respectively; $V_{r i i}, V_{\text {riib }}$ - the volume of realization of industrial innovations per specialist by the establishment and organization selected as a comparison base, respectively; $w_{81}, w_{82}, w_{83}, w_{84}, w_{85}, w_{86}$ are the weight coefficients of the relevant criteria of social efficiency of education, science and production integration $\left(w_{81}+w_{82}+w_{83}+w_{84}+w_{85}+w_{86}=6\right)$.

The criterion of social efficiency of the use of the endowment (target capital fund):

$$
\begin{gathered}
C_{9}=\sqrt[6]{\left(\frac{L_{f i}}{L_{f i b}}\right)^{w_{91}}\left(\frac{A_{l i}}{A_{l i b}}\right)^{w_{92}}\left(\frac{P_{i a}}{P_{i a b}}\right)^{w_{93}}} \times \\
\times \sqrt[6]{\left(\frac{L_{f i}(r)}{L_{f i b}(b)}\right)^{w_{94}}\left(\frac{A_{l i}(r)}{A_{l i b}(b)}\right)^{w_{95}}\left(\frac{P_{i a}(r)}{P_{i a b}(b)}\right)^{w_{96}}},
\end{gathered}
$$

where $L_{f i}, L_{f i b}$ is the level of financial independence evaluated by the establishment and organization selected as a comparison base, respectively; $A_{l i}, A_{l i b}$ - the amount of long-term investments involved by the institution and organization selected as a comparison base, respectively; $P_{i a}, P_{i a b}$ - the profitability of innovation activity of the establishment and organization selected as a comparison base, respectively; $w_{91}, w_{92}, w_{93}, w_{94}, w_{95}, w_{96}$ are the weight coefficients of the relevant criteria of social efficiency of the use of the endowment $\left(w_{91}+w_{92}+w_{93}+w_{94}+w_{95}+w_{96}=6\right)$. 
Following the developed system of SERR criteria, it is possible to form a generalized criterion of SERR:

$$
C_{S E R R}=\sum_{j} C_{j} \times \beta_{j},
$$

where $\beta_{j}-$ is the weight of SERR criteria which are determined by the condition

$$
\sum_{j} \beta_{j}=1,
$$

The weight is determined on the basis of the expert judgment of the decision-maker, in accordance with the weight of a particular type of research carried out by a HEE.

The $\mathrm{X}$ axis is the target subsystem: the process of social efficiency development. This subsystem is represented by the following constituent processes: X1 - assessment of market demands for human resources, educational services, intellectual property objects, unique equipment usage services, scientific knowledge; innovations, consulting services, X2 - identification of the potential of increase in SERR by criteria, X3 ranking of increase in SERR by criteria, X4 - allocation of resources of the endowment in proportion to the increase in SERR by criteria, X5 - assessing the increase in social efficiency of integration of education, science and production by a higher educational establishment (K8), X6 - assessment of increase in SERR.

On the basis of the developed system of assessment criteria of innovation activity efficiency of a higher educational establishment, a structural and logical scheme of SERR assessment has been formed (Fig. 2).

Assessment of market demands for human resources, educational services, intellectual property objects, unique equipment usage services, scientific knowledge; innovations, consulting services

Identification of the potential of increase in SERR by criteria $\mathrm{C}_{1} \ldots \mathrm{C}_{7}$ :

Fig. 2. Sequence of SERR development stages (developed on the basis of [6]).

Thus, at each stage of SERR development, it is possible to achieve maximization of the value of generalized social efficiency criterion of SERR by comparing market demands and opportunities of a HEE by means of the rational allocation of endowment.

The management subsystem (Z-axis) shows the implementation of SER general functions. We specify them: Z1 - defining goals and SER analysis, Z2 development and making management decisions, Z3 planning SER, Z4 - organization and regulation of SER, Z5 - control as a SER tool.

To assess SER, a theoretical and analytical model has been suggested. It is based on a systematic approach that integrates the subsystems described above, which can be analyzed by quantitative and qualitative methods. Mathematical modeling was applied for describing the theoretical and analytical model [20]. It made it possible to obtain a simplified, abstract, formally described model. The latter covers a class of undetermined parameters or vectors, interaction and relations between them that can be described by mathematical operations. The influence of mathematical modeling on economic theory is variegated. Presenting many economic problems in a formalized language makes it possible to avert ambiguity of thinking, clarifies the essence of the problem to a great degree, and vividly demonstrates 
doctrines. In addition, the use of mathematical language helps to specify many economic concepts, systematize theoretical knowledge better, and enrich the conceptual apparatus of economics [21]. The main components of the developed SER theoretical and analytical model has been formally described with the help of the economicmathematical model and the relationships between its components have been analyzed. The first function of
"Setting goals and SER analysis" concerns the component of assessment of market demands in human resources, educational services, objects of intellectual property, unique equipment usage services, scientific knowledge, innovations, consulting services. In the course of SER analysis, the function in question will be influenced by the factors at the macro level. A graphical description of the foresaid is shown in Fig. 3.

Defining goals \& analysis

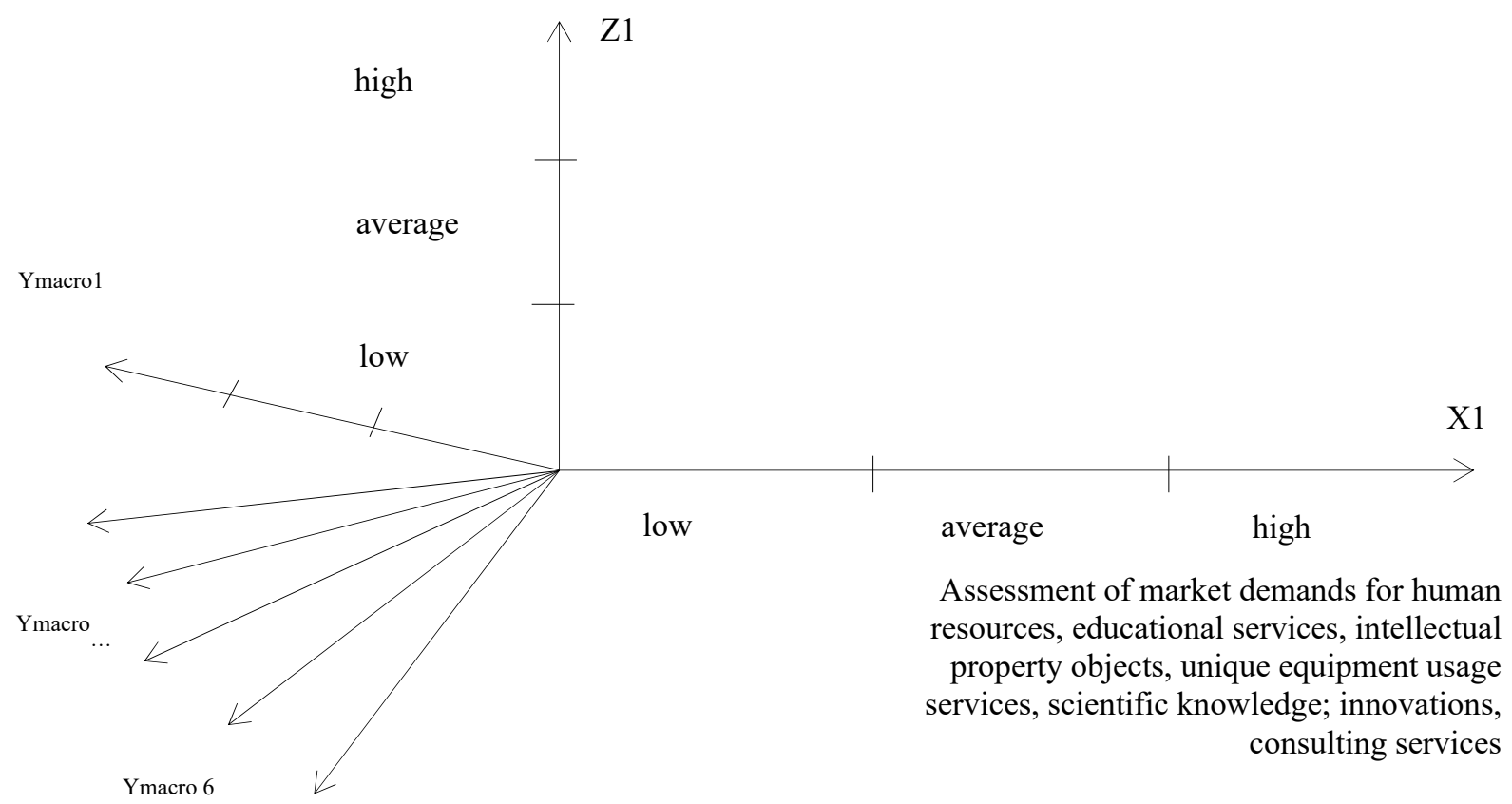

Fig. 3. The degree of dependence of defining goals and SER analysis on the assessment of market demands in human resources, educational services, objects of intellectual property, unique equipment usage services, scientific knowledge, innovations, consulting services in view of micro level factors.

With reference to this aspect, goals are specified in accordance with micro level factors if the goals diverge from the general trend during natural disasters, military events etc. It is up to the researchers to choose the assessment scales taking into consideration the need for detail (for example, from 0 to 1 incrementally).

Graphical description allows to make mathematical dependence of management analysis and goal setting on the assessment of market needs for human resources, educational services, objects of intellectual property, unique equipment usage services, scientific knowledge, innovations, consulting services.

$Z_{1}=a_{1} \times X_{1}+b_{1.1} \times Y_{\text {macro1.1 }}+b_{1.2} \times Y_{\text {macro } 1.2}+$ $b_{1.3} \times Y_{\text {macro1.3 }}+b_{1.4} \times Y_{\text {macro1.4 }}+b_{1.5} \times Y_{\text {macro } 1.5}+$ $b_{1.6} \times Y_{\text {macro1.6 }}+$ const

where $a$ and $b$ are regression coefficients showing the degree of influence of each factor on the function; $X, Y$ are factors that are independent variables that influence the function; const are factors that do not affect the result but are present in the model.

Similarly, we analyze the following relationships and combine the obtained equations into a system of equations [22]:

$$
\left\{\begin{array}{c}
Z_{1}=a_{1} \times X_{1}+b_{1.1} \times Y_{\text {macro } 1.1}+ \\
+b_{1.2} \times Y_{\text {macro } 1.2}+b_{1.3} \times Y_{\text {macro } 1.3}+ \\
+b_{1.4} \times Y_{\text {macro } 1.4}+b_{1.5} \times Y_{\text {macro } 1.5}+ \\
+b_{1.6} \times Y_{\text {macro1.6 }}+\text { const } \\
Z_{2}=a_{2} \times X_{3}+b_{2.1} \times Y_{\text {macro } 2.1}+ \\
+b_{2.2} \times Y_{\text {macro } 2.2}+ \\
+b_{2.3} \times Y_{\text {macro } 2.3}+b_{2.4} \times Y_{\text {macro } 2.4}+ \\
+b_{2.5} \times Y_{\text {macro } 2.5}+b_{2.6} \times Y_{\text {macro } 2.6}+ \\
+b_{2.7} \times Y_{\text {micro } 2.1}+b_{2.8} \times Y_{\text {micro } 2.2}+ \\
+b_{2.9} \times Y_{\text {micro } 2.3}+\text { const } \\
Z_{3}=a_{3} \times X_{2}+b_{3.1} \times Y_{\text {micro } 3.1}+ \\
+b_{3.2} \times Y_{\text {micro3.2 }}+b_{3.3} \times Y_{\text {micro3.3 }}+\text { const } \\
Z_{4}=a_{4} \times X_{2}+b_{4.1} \times Y_{\text {macro } 4.1}+ \\
+b_{4.2} \times Y_{\text {micro } 4.2}+ \\
+b_{4.3} \times Y_{\text {macro } 4.3}+b_{4.4} \times Y_{\text {macro } 4.4}+ \\
+b_{4.5} \times Y_{\text {macro } 4.5}+b_{4.6} \times Y_{\text {macro } 4.6}+\text { const } \\
Z_{5}=a_{5} \times X_{4}+b_{5.1} \times Y_{\text {micro } 5.1}+ \\
+b_{5.2} \times Y_{\text {micro5.2 }}+b_{5.3} \times Y_{\text {micro5.3 }}+\text { const }
\end{array}\right.
$$

It is relevant to use a linear multiple regression program for solving the system of equations. To demonstrate the abovementioned methodology, the results of 3 research issues of Ivano-Frankivsk National 
Technical University of Oil and Gas are taken as an experiment. The expert method was used in the research, which was conducted in 3 stages: experiment $1(Z)$, experiment $2\left(Z^{\prime}\right)$ and experiment $3\left(Z^{\prime \prime}\right)$ (Table 1). To reduce oscillations and offset the error of the results of the experiment, the experts chose the aggregated scale as an example.

Table 1. Calculation of the SER level.

\begin{tabular}{|c|c|c|c|c|c|c|c|c|c|c|c|c|c|}
\hline \multirow{2}{*}{ No } & \multirow{2}{*}{ Standard } & \multicolumn{6}{|c|}{\begin{tabular}{|l|l|} 
SER level Standard correspondence (+/-) \\
\end{tabular}} & \multicolumn{3}{|c|}{ Weight coefficient assignment } & \multicolumn{3}{|c|}{ Adjusted SER level value } \\
\hline & & $\mathbf{Z}$ & $\mathbf{Z}^{\prime}$ & $\mathbf{Z}^{\prime \prime}$ & $\mathbf{Z}$ & $\mathbf{Z}^{\prime}$ & $\mathbf{Z}^{\prime \prime}$ & $\mathbf{Z}$ & $\mathbf{Z}^{\prime}$ & $\mathbf{Z}^{\prime \prime}$ & $\mathbf{Z}$ & $\mathbf{Z}^{\prime}$ & $\mathbf{Z}^{\prime \prime}$ \\
\hline 1 & 1 & 1 & 1 & 2 & + & + & - & 0,35 & 0,6 & 0,1 & 0,35 & 0,6 & 0,2 \\
\hline 2 & 2 & 2 & 3 & 3 & + & - & - & 0,35 & 0,1 & 0,1 & 0,7 & 0,3 & 0,3 \\
\hline 3 & 2 & 1 & 1 & 2 & - & - & + & 0,1 & 0,1 & 0,6 & 0,1 & 0,1 & 1,2 \\
\hline 4 & 1 & 2 & 2 & 2 & - & - & - & 0,1 & 0,1 & 0,1 & 0,2 & 0,2 & 0,2 \\
\hline 5 & 2 & 1 & 1 & 1 & - & - & - & 0,1 & 0,1 & 0,1 & 0,1 & 0,1 & 0,1 \\
\hline Total Value & 6 & 7 & 8 & 10 & $X$ & $X$ & $X$ & 1 & 1 & 1 & 1,45 & 1,3 & 2 \\
\hline
\end{tabular}

Based on table 1, the obtained results were analyzed according to the accepted levels: 0-1,2 - low; 1.21-2.4average; 2.41-3 - high. Also, the dynamics (growth / decline) of the obtained results were determined (Table 2).

Table 2. Defining the SER level and its dynamics.

\begin{tabular}{|c|c|c|c|c|c|}
\hline Stage & Value & $\begin{array}{c}\text { Comparison } \\
\text { between real } \\
\text { value and } \\
\text { accepted } \\
\text { levels }\end{array}$ & $\begin{array}{c}\text { SER } \\
\text { level }\end{array}$ & $\begin{array}{c}\text { Absolute } \\
\text { divergence }\end{array}$ & $\begin{array}{c}\text { Relative } \\
\text { divergence }\end{array}$ \\
\hline $\mathrm{Z}$ & 1,45 & $1,21-2,4$ & average & - & - \\
\hline$Z^{\prime}$ & 1,3 & $1,21-2,4$ & average & $-0,15$ & $-0,11$ \\
\hline$Z^{\prime \prime}$ & 2 & $1,21-2,4$ & average & $+0,7$ & $+0,54$ \\
\hline
\end{tabular}

Thus, with reference to the obtained results, the SER average level has been diagnosed. However, in determining the absolute and relative divergences, we have observed both positive and negative dynamics within one level. While during the first experiment the average SER level $(1,45)$ was found, during the second experiment, the SER level decreased by $11 \%$, although it kept staying at the average level. But long re-diagnosis showed an increase of the SER level by $54 \%$.

\section{Conclusions}

The main competitive advantages of HEE research result from managing innovations. A holistic approach allowed us to construct the integrated model that takes into consideration the possibility of achieving one of the components of the overall research goal - achieving social effect. The constituent models of assessment are complementary and contribute to obtaining complete and comprehensive information related to SER.

The conceptual model based on a holistic approach, is focused on satisfying the interests of specific HEEs and users of research results, on increasing the competitiveness of research results, development of resource and investment capabilities of HEEs as a whole, and, consequently, on improving the standard of life of society by enhancing social trends in the management of scientific research.

The holistic approach to the assessment of SER interpreted by the authors of the article contains 4 subsystems: subsystem of provision, regulatory subsystem, management subsystem, which are described by means of the theoretical and analytical model of SER. The article comes up with an innovative model of SER assessment. An instrument of mathematical modeling has been used to interpret this model, which made it possible to analyze the dependence of its components. The implementation of the model in HEEs will be a viable tool for the demonstration of SER assessment.

Moreover, the model can be used by customers in assessing the significance of researches, in making decisions on giving grants and financing researches, in crediting enterprises and organizations on condition of feasibility of activities that are conducted according to investment projects and business contracts; in setting prices for scientific and technical products.

\section{References}

1. Yu. G. Bondarenko, S.M. Vishniovska, in Abstracts of the reports of the 2nd International Scientific and Practical Conference, Lviv Polytechnic Publishing House, Lviv, 14-16 May 2015

2. V.I. Shinkaruk (ed.), Filosofskyi entsyklopedychnyi slovnyk (Philosophical Encyclopedic Dictionary). (Abrys, Kyiv, 2002), p. 700

3. M.G. Toftul (ed.), Suchasnyi slovnyk z etyky (Modern Dictionary of Ethics). (Publishing House of the I. Franko ZhSTU, Zhytomyr, 2014), pp. 381382

4. V.V. Malyi, The modern concept of pharmaceutical marketing: a holistic approach. Man. Ec. Qual. Assur. Phar. 4, 40-46 (2014)

5. A.M. Bondar, Usage of point evaluation to determine the economic efficiency of the results of scientific work. W. Tavr. St. Agrotech. Un. 12 (1), 172-175 (2012)

6. A.A. Borisov, Dissertation, State Academy of Professional Retraining and Advanced Training of Managers and Investment Specialists, 2010

7. S. Gralka, K. Wohlrabe, L. Bornmann, How to measure research efficiency in higher education? Research grants vs. publication output. J. High. Ed. Pol. Man. 41(3), 322-341 (2019). doi:10.1080/1360080X.2019.1588492 
8. V.A. Karpov, T.S. Koroliova, A.Z. Pidgornyi, Metodyka otsinky efektyvnosti naukovo-doslidnykh robit (Methods of assessment of the effectiveness of research). (OSEU, Odessa, 2005)

9. V.M. Sinchenko, V.I. Pirkin, V.P. Moskalenko, A.V. Shamsutdinova, V.R. Askarov, Improvement of methodology for determining the economic efficiency of scientific development. Sc. Pap. Ins. Bioen. Cr. Sug. Beet. 22, 42-47 (2014)

10. Chuen Tse Kuah, Kuan Yew Wong, Efficiency assessment of universities through data envelopment analysis. Pr. Com. Sc. 3, 499-506 (2011). doi:10.1016/j.procs.2010.12.084

11. T.G. Valderrama, T.L.C.M. Groot, Controlling the Efficiency of University Research in the Netherlands, in Technology Commercialization, ed. by S.A. Thore (Springer, Boston, 2002), pp. 147182. doi:10.1007/978-1-4615-1001-7_10

12. D. Visbal-Cadavid, M. Martínez-Gómez, F. Guijarro, Assessing the Efficiency of Public Universities through DEA. A Case Study. $\begin{array}{llll}\text { Sustainability } & 9 & 1416 & \text { (2017). }\end{array}$ doi:10.3390/su9081416

13. I.E. Zhurba, Substantiation of indicators of efficiency and effectiveness of scientific and technological and innovation policy of Kazakhstan: international aspect. Sc. Ec. 1, 244-248 (2014)

14. R.-L. Shi, N. He, Y. Liu, in Proceedings of the 5th Annual International Conference on Management, Economics and Social Development (ICMESD 2019). doi:10.2991/icmesd-19.2019.10

15. A. Jain, R. Sharma, P.V. Ilavarasan, Measuring research efficiency of higher academic technical institutions of India: Malmquist productivity index approach. Int. J. Intelect Property Manag. 10(1), 5279 (2020)

16. G. Lebedev, O. Krylov, A. Lelyakov, Y. Mironov, V. Tkachenko, S. Zykov, in Intelligent Decision Technologies 2019, ed. by I. Czarnowski, R. Howlett, L. Jain, vol. 142 (Springer, Singapore, 2020), pp. 287-298

17. X. Xiong, G.-L. Yang, Zh.-Ch. Guan, Assessing R\&D efficiency using a two stage dynamic DEa model: A case study of research institutes in the Chinese Academy of Sciences. JOI 3(12), 784-805 (2018)

18. E.V. Romanov, Efficiency assessment of Higher education snstitutions: contradictions and paradoxes. Ed. Sc. J. 10(21), 32-58 (2019). doi:10.17853/19945639-2019-10-32-58

19. O.A. Kovalchuk, O.D Sytnik, Economic and mathematical modeling of process management of motivation of human resources. Bull. Dn. Un. Ec. 7(4), 268-273 (2013)

20. O.A. Kovalchuk, Dissertation, Khmelnytskyi National University, 2012

21. N.R. Draper, H. Smith, Applied Regression Analysis (Wiley-Interscience, Hoboken, 1998), pp. 307-312.
22. O.V. Stakhiv, Dissertation, National Academy of Sciences of Ukraine, 2010

23. A.O. Ustenko, Unifikovana informatsiino-keruiucha systema upravlinnia (The unified informationmanagement system of management). (IvanoFrankivsk, 2012) 